\title{
Responsabilidade social e desenvolvimento sustentável: Um estudo de caso em uma companhia brasileira de alimentos processados
}

\section{Social responsibility and sustainable development: A case study in a Brazilian company of processed food}

Eduardo Botti Abbade

Doutorando em Agronegócios - UFRGS - Brasil

e-mail: eduardo@unifra.br

Giana de Vargas Mores

Pós-graduação em Agronegócios - UFRGS - Brasil

e-mail: gimoraes@unifra.br

Recebido em 15 de fevereiro de 2012. Alterado em 23 de maio de 2012. Aprovado em 05 de novembro de 2012

Editor Responsável: Edson Roberto Scharf, Dr.

Processo de avaliação por double blind review

\begin{abstract}
Resumo
A responsabilidade social corporativa (RSC) e o desenvolvimento sustentável (DS) são temas de investigações acadêmicas que tem atraído grande atenção nas últimas décadas em virtude das necessidades sociais e ambientais. Também se considera que as empresas assumem um papel decisivo na manutenção e construção de um ambiente alinhado com as necessidades da sociedade e das gerações futuras. Este estudo é focado nas ações e iniciativas de uma grande empresa de alimentos processados objetivando fazer uma relação entre a teoria e as práticas da empresa em termos de RSC e DS. O método empregado é o estudo de caso com análise de dados secundários obtidos em documentos da empresa. Os resultados demonstram que a empresa apresenta iniciativas em todas as importantes esferas da sustentabilidade. Entretanto considera-se que grande parte de suas ações sejam voltadas para as comunidades locais onde existem unidades da empresa instaladas. Além disso, também foram identificadas ações em prol do desenvolvimento de uma cadeia produtiva sustentável por meio do desenvolvimento de produtores rurais e capacitação de processos logísticos.
\end{abstract}

Palavras-chave: Desenvolvimento Sustentável; Responsabilidade Social Corporativa; Cidadania Corporativa; Desempenho Social; Desempenho Ambiental.

\begin{abstract}
Corporate social responsibility (CSR) and sustainable development (SD) are subjects of academic research that has attracted great attention in recent decades because of social and environmental needs. It is also considered that companies assume a decisive role in maintaining and building an environment aligned with the needs of society and future generations. This study is focused on actions and initiatives of a large company of processed foods aiming to establish a relationship between theory and practices of these actions in terms of CSR and DS. The methodological procedure was the study case with analyses of data obtained in official documents of the company. The results show that the company has initiatives in all important spheres of sustainability. However it is considered that most of its actions are aimed at local communities where the company has business units installed. In addition, actions have been identified focused on the
\end{abstract}


development of a sustainable supply chain through the development and training of farmers and logistics processes.

KEY-WORDS: Sustainable Development; Corporative Social Responsibility; Corporate Citizenship, Social Performance, Environmental Performance.

\section{Introdução}

O debate acadêmico e prático a respeito das boas práticas organizacionais com foco na responsabilidade social e sustentabilidade representa um tópico de preocupação crescente. Estudos relacionados à sustentabilidade e a preocupação coorporativa com aspectos ambientais e sociais têm emergido com grande força nos últimos anos de modo a abordar questões ambientais importantes (ELKINGTON, 1998; NEWELL e MURO, 2006; SCHAEFER, 2004; WAGNER, 2005). Considera-se ainda que organizações devam desempenhar papeis socialmente e ambientalmente responsáveis, pois órgãos públicos não são capazes de atender sozinhos os requisitos da sustentabilidade. Além disso, a postura sustentável e socialmente responsável das organizações pode conferir a elas vantagens competitivas sustentáveis já que trabalham com imagem corporativa e adequação às exigências do mercado consumidor.

Este estudo objetiva analisar as práticas e posturas estratégicas da Brasil Foods S.A. (BRF) voltadas para a Responsabilidade Social Corporativa (RSC) e Desenvolvimento Sustentável (DS). Essa empresa brasileira de grande porte atua nos segmentos de alimentos processados e lácteos e sua escolha se deu pelo fato desta apresentar iniciativas constantes com foco na sociedade e no ambiente ecológico. Além disso, a empresa faz parte da carteira de empresas do índice de sustentabilidade da Bolsa de Valores de São Paulo (ISE) apresentando uma participação de 7,651\% no índice (BM\&F BOVESPA, 2011). Assim, este estudo de caso relata as práticas sustentáveis da BRF e confronta as mesmas com aspectos e posturas teóricas.
A proposta central deste estudo está intimamente relacionada com o contexto das práticas de RSC por considerar a importância do papel das corporações na sociedade (PRESTON, 1975, SCHWARTZ; CARROLL, 2008) e as preocupações relacionadas às transformações do planeta em termos econômicos, sociais e ambientais (GAWOR, 2008). Este estudo apresenta uma justificativa teórica relevante ao passo que procura avançar na teoria e no conhecimento científico existente a respeito dos temas investigados, ou seja, RSC e DS. Além disso o estudo também apresenta uma relevância prática importante já que busca divulgar ações estratégicas de uma corporação relacionadas à RSC e DS assim como analisar suas pertinências e lacunas.

\section{Responsabilidade sócio-ambiental e desenvolvimento sustentável coorporati- vos}

Este estudo está sedimentado em aspectos teóricos e práticos relacionados à Responsabilidade Social Corporativa (RSC) e ao Desenvolvimento Sustentável (DS). As divergências e convergências desses dois conceitos são discutidas a seguir de modo a elucidar suas complementaridades e intersecções. A RSC é tema de ampla discussão acadêmica e apresenta um foco acentuado nas práticas e iniciativas empresarias (principalmente grandes corporações). Logo, a RSC considera o papel das corporações e suas responsabilidades para com a sociedade (GALBREATH, 2009) sob uma ótica estratégica (STEAD e STEAD, 2000).

A RSC era compreendida como ações filantrópicas e assistenciais. Entretanto, esse conceito apresenta uma evolução onde foram sendo incorporados novos constructos e dimensões de análise como ética nos negócios, gestão dos stakeholders, cidadania corporativa e sustentabilidade (SCHWARTZ e CARROLL, 2008). Considera-se ainda a existência de uma proximidade teórica acentuada entre os 
conceitos de RSC e DS já que esse último conceito é compreendido sou uma ótica macro-analítica envolvendo organizações, instituições e sociedade de modo a obter crescimento e desenvolvimento de forma sustentável (WCDE, 1987). Existe uma falta de consenso e delimitação de fronteiras conceituais para as definições de RSC e DS, sendo que muitas vezes esses conceitos são tratados como sinônimos (PEREZBATRES, MILLER e PISANI, 2010). Considera-se que o conceito de RSC pode ser encarado como as práticas e posturas corporativas adotadas em prol da sociedade e do ambiente natural e que devem estar alinhadas com os preceitos do DS.

Existem posicionamentos e posturas teóricas diversas relacionadas à $\mathrm{RSC} \mathrm{e}$ à sustentabilidade. Davis e Blomstrom (1975) definem a responsabilidade social como a preocupação com o interesse público. Contribuindo com essa visão, Carroll (1979, 1991, 1999) sugere um modelo de responsabilidade social das empresas que abrangem quatro dimensões: econômica, legal, ética e filantrópica. A primeira dimensão, responsabilidade econômica, busca prover lucratividade para os shareholders, bons empregos para os colaboradores e produtos de qualidade para os consumidores. A segunda dimensão, responsabilidade legal, refere-se ao cumprimento das leis e regulamentações vigentes. A terceira dimensão, responsabilidade ética, refere-se à condução dos negócios de forma a promover a moralidade e justiça. A quarta dimensão, responsabilidade filantrópica, envolve iniciativas e contribuições voluntárias em prol da sociedade.

Outro modelo semelhante é o de Lantos (2001) que classifica a RSC em três dimensões: ética, altruísta e estratégica. A RSC ética envolve o cumprimento da moralidade baseada na responsabilidade econômica, legal e ética. A RSC altruísta representa o cumprimento das responsabilidades filantrópicas organizacionais indo além de meramente prevenir possíveis ameaças e sanar deficiências de bem estar público sem ter foco específico em retorno financeiro. Já a RSC estratégica refere-se a ações filantrópicas que trarão algum benefício para a empresa.

Sethi (1979) e Frederick (1994) adotam o termo responsividade social definido como a adaptação do comportamento corporativo às necessidades sociais, antecipando-se na solução de seus problemas. Assim, considerando os posicionamentos teóricos citados, observa-se que o foco da responsabilidade social é o bem estar da sociedade como um todo. Entretanto, as práticas e iniciativas corporativas focadas nesse objetivo apresentam divergências importantes de serem consideradas. Freeman (1984) considera que para que uma empresa seja socialmente responsável, ela precisaria considerar em suas estratégias e valores as expectativas dos stakeholders. Dessa forma, considera-se de extrema importância a posição corporativa em exercer papel socialmente responsável, construindo e mantendo relações de longo prazo com stakeholders externos (BENDIXEN e ABRATT, 2007). Resgatando as premissas da interdependência e relações sistêmicas da cadeia produtiva, para que as empresas atuantes em uma determinada cadeia sejam consideradas socialmente responsáveis e sustentáveis é necessário uma integração entre os agentes da cadeia envolvendo uma disseminação de iniciativas, práticas, políticas e tecnologias. Uma cadeia só poderá ser considerada socialmente responsável e sustentável quando os agentes atuantes desenvolvem ações conjuntas de sustentabilidade econômica, social e ambiental, uma vez que estão integrados de forma sistêmica e interdependentes (TENÓRIO, 2006).

Complementando os conceitos e modelos anteriores, Neves e Bento (2005) apresentam duas novas categorias da RSC que são as categorias interna e externa. A categoria interna refere-se aos compromissos das organizações com os interesses de seus stakeholders internos e os impactos ambientais dos processos de gestão. Assim, 
a empresa busca promover ações que favoreçam seus colaboradores, como melhorias de condições de trabalho, qualidade de vida, oportunidades de crescimento e desenvolvimento além de investimentos em gestão ambiental. Já a categoria externa está relacionada aos interesses dos stakeholders externos como a comunidade local, consumidores, fornecedores, parceiros e outros públicos de interesse. Logo as ações externas priorizam a implementação de programas solidários, programas corporativos voluntários e programas de conservação ambiental.

Outra contribuição importante que embasa este estudo é o modelo de Galbreath (2009) que afirma que a RSC não se restringe somente ao cumprimento das responsabilidades sociais, mas também está relacionada ao desenvolvimento societal. As ações de RSC dessa forma desempenham um papel amplo na sociedade indo desde o desenvolvimento da própria empresa até o desenvolvimento global. Ainda essas posturas e ações estratégias da empresa podem provocar impactos positivos na: qualidade de vida, no crescimento econômico e prosperidade, realização e significado, competitividade, reputação (local, nacional e global) e sustentabilidade (GALBREATH, 2009). A figura 1 demonstra essa perspectiva de amplitude das ações de RSC.

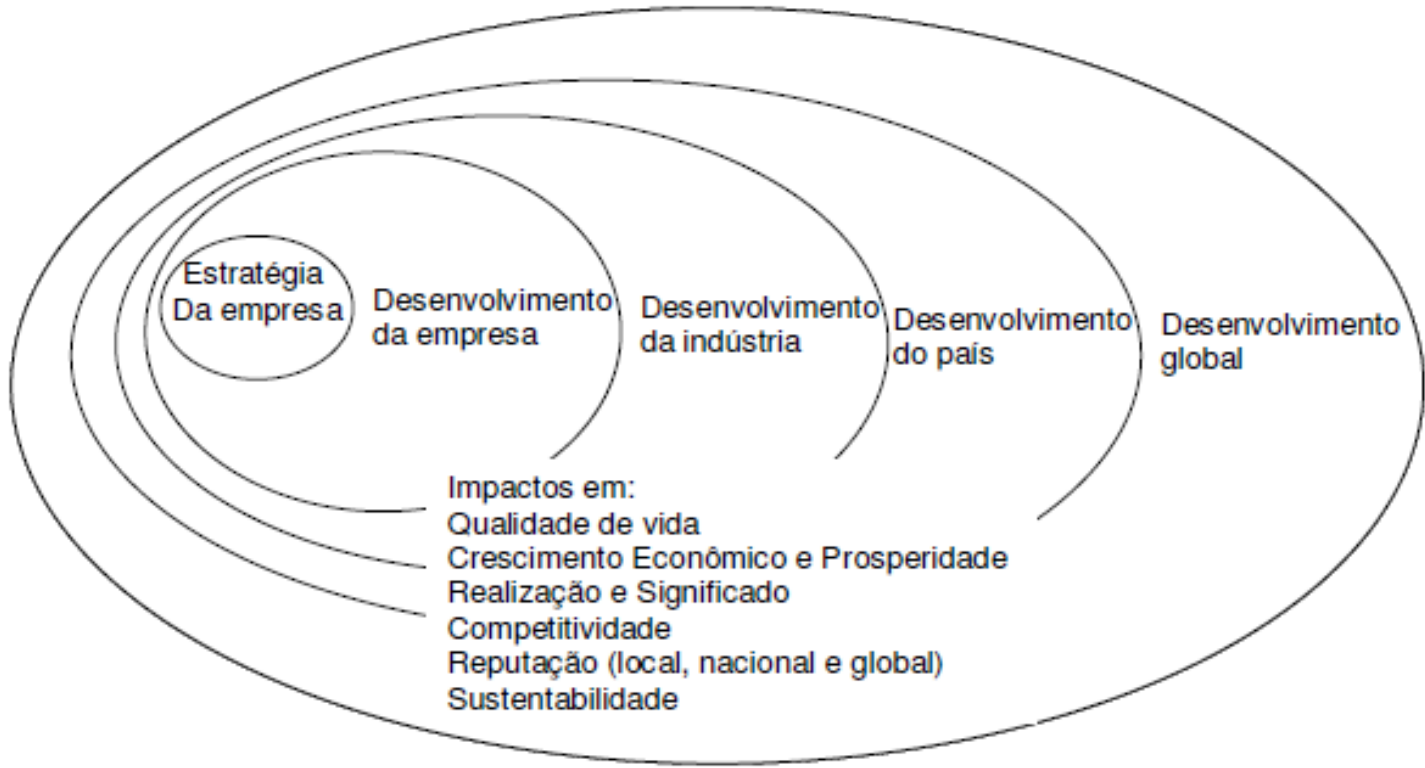

Figura 1 - Estratégia no contexto da sociedade

Fonte: Galbreath (2009, p. 122)

Outros elementos importantes tomam uma posição importante nas ações de RSC. Termos e conceitos chaves como ética nos negócios, stakeholders, cidadania corporativa e sustentabilidade embasam os pressupostos teóricos da RSC (SCHWARTZ e CARROLL, 2008). A ética nos negócios pode ser considerada como a noção e entendimento do certo e do errado (VELASQUEZ, 2006), concentran- do-se em como as normas morais se aplicam às políticas de negócios, instituições e comportamento (SCHWARTZ e CARROL, 2008). Já a teoria dos Stakeholders afirma que (1) as empresas têm relacionamentos com muitos grupos que afetam e que são afetados por suas decisões; (2) a teoria tem preocupação com a natureza desses relacionamentos em termos de processos e resultados para a empresa e 
seus stakeholders; (3) o interesse de todos os stakeholders tem valores intrínsecos e nenhum conjunto de interesses é assumido ou dominado por outros; e (4) o foco é dado à tomada de decisões gerenciais (JONES e WICKS, 1999). Cidadania corporativa é definida como a gestão de uma empresa e de suas influências sobre as relações com o resto da sociedade (SCHWARTZ e CARROL, 2008).

Por fim, o conceito de sustentabilidade afirma que "desenvolvimento sustentável é o desenvolvimento que atenda às necessidades do presente sem comprometer a capacidade das gerações futuras satisfazerem suas próprias necessidades" (WCDE, 1987). Uma das contribuições mais importantes dos últimos anos foi o desenvolvimento do conceito do
Triple-Botton-Line (TBL) que incorpora, além da dimensão econômico-financeira, as dimensões sociais e ambientais na gestão e performance empresarial (ELKINGTON, 1998). Contribuindo com o modelo tradicional do TBL, Tencati e Zsolnaj (2009) acrescentam que a sustentabilidade empresarial depende da habilidade da empresa em gerenciar aspectos ambientais, sociais, culturais e econômicos. Dessa forma, por meio de um maior envolvimento e geração de valor com os stakeholders, pode-se partir para uma perspectiva de Multiple Botton Line. O modelo proposto por Carter e Rogers (2008) explora essa relação das dimensões do desempenho sustentável em nível organizacional e interorganizacional. Esso modelo é ilustrado na figura 2.

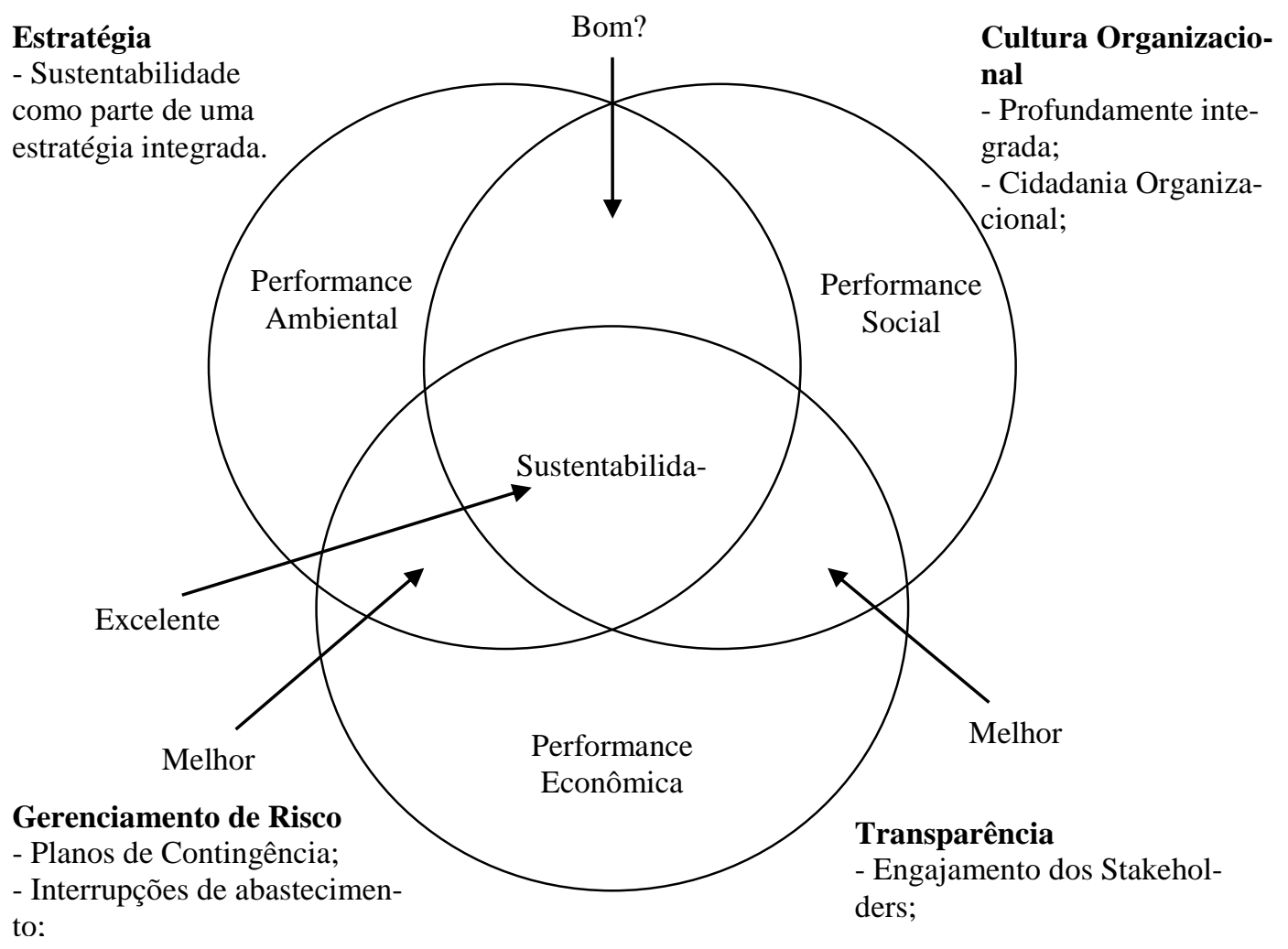

Figura 2 - Intersecções entre as dimensões da sustentabilidade

Fonte: Adaptado de Carter e Rogers (2008).

Um dos pontos centrais do modelo que apesar de os bons resultados alcançados por meio da integração das performanproposto por Carter e Rogers (2008) é de 
ces organizacionais (ex. econômica e social; ou econômica e ambiental), a verdadei-

ra sustentabilidade corporativa será alcançada mediante a integração das três dimensões da sustentabilidade propostas por Elkington (1998). Com isso, as organizações devem proceder com foco no longo prazo e voltadas para a integração das performances econômica, social e ambiental (CARTER e ROGERS, 2008). Para que isso seja alcançado ao nível da cadeia de suprimentos, a performance sustentável deve ser integrada e alinhada aos preceitos estratégicos de seus participantes. Também é necessário um esforço no sentido de incorporar elementos da sustentabilidade na cultura organizacional dos agentes econômicos envolvidos. Um bom gerenciamento de risco com planos de contingência e definição dos limites e responsabilidades dos agentes deve der bem construído e um relacionamento transparente entre os stakeholders deve ser priorizado (CARTER e ROGERS, 2008).

Logicamente, seguindo uma perspectiva de cooperação interorganizacional e atuação conjunta em cadeias produtivas, o valor gerado pelas empresas baseado nas três dimensões da sustentabilidade são direcionados para uma gama ampla de stakeholders. Logo, pode-se constatar uma relação bastante próxima entre os conceitos de RSC, ética nos negócios, cidadania corporativa, teoria dos stakeholders e sustentabilidade. Ainda, é possível associar esses conceitos com as perspectivas de análise interorganizacional com foco em cadeias de produção e suprimento sustentáveis.

\section{Procedimentos metodológicos}

Este estudo é definido como um estudo de caso, classificado como descritivo no que diz respeito aos seus objetivos. O método de estudo de caso é indicado para estudos que busquem investigar a realidade do objeto de estudo de forma aprofundada e detalhada (YIN, 2005). As- sim, foi selecionada uma empresas de grande porte e com capital aberto e ações negociadas na BOVESPA, atuante no setor industrial de alimentos processados. Portanto, o nível e a unidade de análise são organizacionais.

Este estudo é classificado prioritariamente como qualitativo, apesar de serem analisados alguns dados quantitativos. Os dados analisados foram dados secundários sendo empregada a análise documental. Os dados foram obtidos por meio de uma análise de informações obtidas no site da empresa. Estes documentos compreendem relatórios anuais, balanços sociais e patrimoniais, demonstrativos de resultados e divulgação de ações vinculadas aos objetivos do estudo. Todos os documentos tiveram como ano base o ano de 2010. O objetivo foi analisar as informações coletadas de acordo com os objetivos do presente estudo visando descrever os perfis das empresas quando suas ações de responsabilidade social e sustentabilidade. A análise dos dados se deu de forma descritiva e interpretativa. As informações divulgadas pela empresa assim como os valores e dados quantitativos foram analisados à luz das teorias que dão embasamento teórico ao estudo.

\section{Resultados do estudo de caso: BRF - Brasil Foods S/A}

Esta seção apresenta os resultados do estudo. Inicialmente a empresa é caracterizada de forma descritiva. Em seguida são apresentadas as iniciativas e ações divulgadas pela empresa com foco na responsabilidade social e sustentabilidade corporativa. Essas ações e os respectivos desempenhos organizacionais são subdivididos em desempenho social interno, desempenho social externo, desempenho ambiental e desempenho econômico.

\subsection{Caracterização da Empresa}

A Brasil Foods (BRF) pode ser considerada uma das maiores empresas 
industriais de alimentos processados do mundo em termos de valor de mercado. No ano de 2010 alcançou a posição de terceira maior exportadora do Brasil (Ministério do Desenvolvimento, Indústria e Comércio Exterior, 2011; Relatório Anual, 2010). Sua carteira de produtos é composta por mais de 3 mil itens nos segmentos de aves, suínos, bovinos, processados de carne, leite, lácteos, margarinas, massas, pratos e vegetais congelados e outros produtos processados. Além disso atua no mercado com diversas marcas onde as principais são Perdigão, Sadia, Qualy, Doriana, Becel, Rezende, Batavo, Elegê, Wilson, Cotochés, Miss Daisy, Deline, Avipal, Texas Burger, Speedy Pollo, Turma da Mônica, Chester, Fribo e Freski.

A empresa possui uma estrutura operacional e organizacional composta por 60 fábricas instaladas em todas as regiões do Brasil, além de três localizadas no exterior (produção de lácteos na Argentina e unidades da Plusfood na Inglaterra e Holanda). No exterior, possui 24 escritórios comerciais e relaciona-se com mais de 5 mil clientes em 140 países dos cinco continentes. Conta ainda com cerca de 13 mil funcionários. Além disso, no ano de 2010 comercializou 5,7 milhões de toneladas de produtos e contabilizou uma receita líquida de $\mathrm{R} \$ 22,7$ bilhões $(59,6 \%$ no mercado interno e $40,4 \%$ no mercado externo).

\subsection{Sustentabilidade na BRF - Brasil Foods S.A.}

A sustentabilidade é considerada pela empresa uma preocupação estratégica. Sendo assim, a BRF desenvolve ações e programas com foco sustentável baseados em seis pilares. O primeiro - Compromisso total com sustentabilidade - refere-se à ações como incluir critérios de sustentabilidade nas decisões de investimentos e novos projetos/produtos da organização; atrelar remuneração variável/bônus dos principais executivos às metas de sustentabilidade; obter conformidade da gestão aos principais padrões e certificações em sustenta- bilidade; realizar auditoria constante nas operações da Empresa e nos fornecedores; e promover a manutenção/entrada nos principais índices de sustentabilidade.

O segundo pilar - alavancar a sustentabilidade na cadeia de valor - baseia-se em ações como firmar posição como indutor da sustentabilidade na agricultura brasileira; identificar e reduzir os principais riscos sociais e ambientais na cadeia de valor (do campo à mesa); desenvolver novas oportunidades na cadeia de valor. $\mathrm{O}$ terceiro pilar - engajamento com públicos de relacionamento - procura envolver os públicos de interesse nas tomadas de decisões; aprimorar o processo de prestação de contas em assuntos voltados à sustentabilidade, priorizando transparência e públicos importantes. O quarto pilar - promover o consumo sustentável - focaliza em realizar investimento relevante para que os produtos da empresa estejam cada vez mais adequados aos critérios de saudabilidade (redução dos níveis de sódio, açúcar, gordura trans e saturada); observar a inclusão social no mercado consumidor como uma oportunidade de negócio para a empresa. O quinto pilar - valorização do capital humano - está relacionado com ações que visam valorizar e capacitar mão de obra local; aprimorar práticas de gestão para elevar os níveis de satisfação dos funcionários; incluir a educação para a sustentabilidade na estratégia de desenvolvimento organizacional; orientar os funcionários para atuar como agentes de sustentabilidade. Finalmente, o sexto pilar - adaptação a mudanças climáticas - visa o controle e redução de impactos ambientais (consumo e emissões) das operações da empresa, tornandose uma companhia com contribuição positiva para o cenário de mudanças climáticas; participar de movimentos setoriais e compromissos públicos voltados para redução das mudanças climáticas.

\subsubsection{Desempenho social interno}

A dimensão social com foco interno refere-se a ações e iniciativas da empre- 
sa com um cunho social em prol das comunidades internas da empresa como colaboradores, funcionários e demais agentes da cadeia de suprimentos. São apresentadas iniciativas implementadas pela empresa relativas à gestão de pessoas, fornecedores e consumidores (stakeholders).

Analisando as iniciativas relacionadas à gestão de pessoas da BRF constatouse que em 2010 a empresa desenvolveu alguns programas importantes de treinamento e desenvolvimento com foco na qualidade de vida, saúde e segurança no trabalho. Os dados revelam a ocorrência de uma redução de $35 \%$ na taxa de frequiência de acidentes com afastamento em 2010. Outra constatação importante é a de que cerca de $90 \%$ dos colaboradores da empresa são representados por comitês formais de segurança que atuam na redução e eliminação de acidentes ou doenças de trabalho. Essas foram os dados obtidos julgados mais pertinentes e relacionados com os princípios da RSC de gestão de pessoas.

Com relação à gestão do relacionamento com fornecedores, a BRF lançou o programa Supply Chain de Classe Mundial que prevê a identificação e adoção das melhores práticas globais de cadeia de suprimento. Com isso, o programa exige que a área de suprimentos da BRF migre para o conceito de procurement desenvolvendo negócios e fornecedores. Assim, os negociadores devem ter uma compreensão mais ampla no negócio. A BRF seleciona seus fornecedores avaliando a viabilidade comercial, competitividade de custo, capacitação técnica, situação econômica e financeira e alinhamento com as políticas e diretrizes sociais e ambientais. No ano de 2010, 39,4\% das compras com fornecedo- res foram realizadas nas regiões próximas às principais unidades da BRF. Com os integrados (criadores de aves e suínos), produtores de bovinos e leite, esse índice é de $100 \%$.

Outro programa importante é o Programa de Monitoramento da Cadeia de Fornecedores que reúne políticas, práticas e procedimentos que alinham a BRF e seus fornecedores impulsionando a sustentabilidade na cadeia de valor. Por meio de um mapeamento a BRF identificou risco nas áreas de suprimentos, farelo, óleo, grãos, bovinos, lácteos e logística. Como forma de minimizar o risco de ocorrências danosas, foram reforçadas as iniciativas de controle por meio de clausulas contratuais mais rígidas.

Com relação à gestão do relacionamento com os consumidores, a BRF também desenvolve práticas importantes. Todos os seus produtos são submetidos a uma avaliação de impactos à saúde e segurança em diversas fases de seu ciclo de vida. Além disso, como forma de avaliar a satisfação de seus consumidores, a empresa realizou uma pesquisa com 31.176 pessoas onde aproximadamente $99 \%$ demonstraram satisfação com os produtos da empresa. Também no ano de 2010 a empresa recebeu 373.682 manifestações de consumidores onde $6 \%$ foram reclamações de produtos e críticas. As demais manifestações foram relativas à busca de informações, solicitações de receitas e outros temas diversos.

A seguir, na tabela 1, são apresentados os indicadores sociais internos com base dos dados financeiros do Balanço Social publicado pela empresa no modelo IBASE dos anos de 2009 e 2010.

Tabela 1 - Indicadores sociais internos do Balanço Social IBASE 2010

\begin{tabular}{l|ccc|ccc}
\hline & \multicolumn{3}{|c|}{2010} & \multicolumn{3}{c}{2009} \\
\hline \multirow{2}{*}{ Indicadores sociais internos } & $\begin{array}{c}\text { Valor } \\
\text { (R\$ }\end{array}$ & $\begin{array}{c}\text { \% sobre } \\
\text { milhões) }\end{array}$ & $\begin{array}{c}\text { \%PB sobre } \\
\text { RL }\end{array}$ & $\begin{array}{c}\text { Valor } \\
\text { (R\$ mi- } \\
\text { lhões) }\end{array}$ & $\begin{array}{c}\text { \% sobre } \\
\text { FPB }\end{array}$ & $\begin{array}{c}\text { \% sobre } \\
\text { RL }\end{array}$ \\
\hline Alimentação & 128,10 & $3,63 \%$ & $0,56 \%$ & 156,95 & $4,97 \%$ & $0,75 \%$ \\
Encargos sociais compulsórios & 836,30 & $23,72 \%$ & $3,69 \%$ & 629,97 & $20,00 \%$ & $3,01 \%$ \\
Previdência privada & 11,53 & $0,33 \%$ & $0,05 \%$ & 11,21 & $0,36 \%$ & $0,05 \%$
\end{tabular}

Revista de Negócios, ISSN 1980-4431, Blumenau, Brasil, v.18, n. 2, p. 27-43, Abril/Junho de 2013. 


\begin{tabular}{l|ccc|ccc} 
Saúde & 85,41 & $2,42 \%$ & $0,38 \%$ & 100,16 & $3,18 \%$ & $0,48 \%$ \\
Segurança e saúde no trabalho & 14,29 & $0,41 \%$ & $0,06 \%$ & 21,63 & $0,69 \%$ & $0,10 \%$ \\
Educaçąo, capacitação e desen- & 3,66 & $0,10 \%$ & $0,02 \%$ & 6,08 & $0,19 \%$ & $0,03 \%$ \\
volvimento profissional & 90,99 & $2,58 \%$ & $0,40 \%$ & 32,67 & $1,04 \%$ & $0,16 \%$ \\
Transportes & 0,00 & $0,00 \%$ & $0,00 \%$ & 14,4 & $0,46 \%$ & $0,07 \%$ \\
Cultura & 1,28 & $0,04 \%$ & $0,01 \%$ & 1,15 & $0,04 \%$ & $0,01 \%$ \\
Creches ou auxílio-creche & 23,13 & $0,66 \%$ & $0,10 \%$ & 26,76 & $0,85 \%$ & $0,13 \%$ \\
Participação nos lucros ou resul- & 26,50 & $0,75 \%$ & $0,12 \%$ & 47,41 & $1,51 \%$ & $0,23 \%$ \\
tados & $\mathbf{1 . 2 2 1 , 1 9}$ & $\mathbf{3 5 \%}$ & $\mathbf{5 \%}$ & $\mathbf{1 . 0 4 8 , 3 8}$ & $\mathbf{3 3 , 3 2 \%}$ & $\mathbf{5 , 0 1 \%}$ \\
\hline Outros & & & & & & \\
\hline Total & &
\end{tabular}

Nota: FBP = Folha de Pagamento Bruta; RL = Receita Líquida.

Fonte: Adaptado do Balanço Social BRF (2010).

Pode-se observar que os gastos realizados pela BRF em alimentação, saúde, segurança, educação profissional e cultura apresentaram decréscimos acentuados em 2010 comparativamente ao ano de 2009. Já os gastos com encargos sociais compulsórios e transportes apresentaram crescimentos acentuados. Os valores gastos com previdência privada e creches não apresentaram alterações significativas. Apesar dos valores gastos totais em 2010 terem sido maiores do que os de 2009, de modo geral, o ano de 2010 apresenta um desempenho social interno inferior ao de 2009.

\subsubsection{Desempenho social externo}

A dimensão social com foco externo remete a ações e iniciativas de cunho social da corporação onde o público alvo beneficiado são os públicos externos e a sociedade geral. Na dimensão referente ao desempenho social externo da BRF foram constatadas algumas práticas e iniciativas da empresa que corroboram com sua postura sustentável. O foco dos investimentos de 2010, que totalizaram $\mathrm{R} \$ 2,2$ milhões, foram para questões relacionadas à educação e meio ambiente. Além disso, a abrangência dos projetos é relativa principalmente aos municípios onde a empresa possui unidades de negócio e produção. Por meio de chamada pública, BRF obteve a inscrição de 160 projetos sendo que desses 32 foram selecionados e 24 concluídos em 2010. Os projetos apresentam um direcionamento maior para ações de melhoria na educação, inclusão social de deficientes, conscientização e preservação ambiental e apoio a negócios sustentáveis. A empresa ainda divulga que foram beneficiadas 27 mil pessoas com os projetos implementados. A seguir, no quadro 1, são apresentados alguns dos projetos desenvolvidos pela BRF.

Quadro 1 - Projetos sociais de âmbito externo da BRF

\begin{tabular}{|c|l|}
\hline Projeto social & \multicolumn{1}{c|}{ Descrição } \\
\hline \multirow{2}{\text{Tempodeem-}}{$\begin{array}{c}\text { Contando com a participação do Instituto Camargo Corrêa, do Sebrae e de parceiros locais, } \\
\text { preender }\end{array}$} & $\begin{array}{l}\text { esse projeto, iniciado em 2009, foi estruturado para um período de cerca de dois anos e } \\
\text { meio e tem como objetivo alavancar o desenvolvimento sustentável das regiões de Lucas do } \\
\text { o projeto Fazer dar Certo, que capacitou 150 jovens para o empreendedorismo sustentável. } \\
\text { Em Nova Mutum e Tapurah, prevê o fortalecimento de agronegócios geridos por essas } \\
\text { comunidades, bem como a criação de dois viveiros de mudas nativas, florestais e frutíferas } \\
\text { para uso na recuperação da biodiversidade da região e como fonte de renda adicional aos } \\
\text { produtores rurais e suas famílias. }\end{array}$ \\
\hline $\begin{array}{c}\text { Concórdia Digi- } \\
\text { tal }\end{array}$ & $\begin{array}{l}\text { Realizado em parceria com a Prefeitura Municipal de Concórdia e o Instituto Jaborandi, } \\
\text { tem por objetivo transferir a metodologia da informática educacional para a rede municipal }\end{array}$ \\
\hline
\end{tabular}




\begin{tabular}{|c|l|}
\hline & $\begin{array}{l}\text { de ensino. Procura que a informática seja usada de forma inovadora em sala de aula apoian- } \\
\text { do alunos e professores na construção do conhecimento. Entrou na sua fase final em 2010, } \\
\text { denominada Professores em Rede. No total, 12 escolas municipais engajaram-se no piloto. }\end{array}$ \\
\hline Estação Digital & $\begin{array}{l}\text { Focado na inserção digital, é desenvolvido em Bom Conselho (PE) e conta com a parceria } \\
\text { da Universidade de Pernambuco, Fundação Banco do Brasil, Prefeitura de Bom Conselho, } \\
\text { empresas Oi e IBM. Em 2010, foram capacitados 221 jovens e adultos. }\end{array}$ \\
\hline $\begin{array}{c}\text { Centro Educaci- } \\
\text { onal para Pesso- } \\
\text { as com Deficiên- } \\
\text { cia }\end{array}$ & $\begin{array}{l}\text { Em 2010, foram capacitados 59 alunos em Videira (SC) em ensino fundamental, ensino } \\
\text { médio, oficina de artes, educação digital por meio do curso Aprenda a Clicar e capacitação } \\
\text { para o trabalho. Em Marau (RS), 49 alunos receberam lições de ensino fundamental, Libras, } \\
\text { braille, educação digital e oficina de artes. }\end{array}$ \\
\hline $\begin{array}{c}\text { Ações com cata- } \\
\text { dores de lixo }\end{array}$ & $\begin{array}{l}\text { A BRF participa da estruturação do Instituto do Lixo e Cidadania, que congrega entidades } \\
\text { de catadores de todo o Estado do Paraná. Iniciada em abril de 2010, a iniciativa tem dura- } \\
\text { ção de um ano e visa ainda atender à Política Estadual de Resíduos Sólidos. O projeto apóia } \\
\text { o surgimento de cooperativas de catadores dedicadas a recolher as embalagens pós- } \\
\text { consumo para serem vendidos a recicladores. }\end{array}$ \\
\hline Ação Social & $\begin{array}{l}\text { O projeto busca facilitar o acesso a serviços nas áreas de saúde, cidadania e educação, além } \\
\text { de atividades voltadas à cultura, lazer e práticas esportivas. Dirigido às comunidades pró- } \\
\text { ximas às unidades fabris é uma iniciativa para melhorar a qualidade de vida da população. } \\
\text { Para colocar em prática as atividades previstas, a BRF faz parcerias com instituiçóes e } \\
\text { empresas locais atuando como agente de mudança social. Desde a sua criação, em 2003, } \\
\text { foram feitos 300 mil atendimentos, sendo 68.377 em 2010. }\end{array}$ \\
\hline
\end{tabular}

Fonte: Adaptado do Brasil Foods (2010).

Pode-se constatar que a BRF desenvolve uma série de projetos de cunho social importantes. Entretanto, observa-se que essas iniciativas têm um cunho local em termos de amplitude e alcance. Logo, o desenvolvimento obtido pelas ações descritas no quadro 1 é focado na localidade de unidades da BRF (GALBREATH, 2009). Além disso, são ações de cunho assistencialista apresentando uma mescla de orientações éticas, altruístas e estratégicas (LANTOS, 2001).

Quadro 2 - Projetos sociais voltados para o esporte na BRF
A empresa também desenvolve algumas iniciativas voltadas para o esporte. Criado em 2007, a BRF realiza anualmente o Programa 5 km Perdigão que consiste em na conscientização dos funcionários e da comunidade a respeito da importância da prática de atividades físicas. Além disso, a empresa também opera suas ações com foco em três alicerces apresentados no quadro 2.

\begin{tabular}{|c|l|}
\hline $\begin{array}{c}\text { Projeto } \\
\text { Social }\end{array}$ & \multicolumn{1}{c|}{ Descrição } \\
\hline $\begin{array}{c}\text { Atleta } \\
\text { para o }\end{array}$ & $\begin{array}{l}\text { Parcerias com o Sesi em sete municípios onde possui unidades industriais, com o foco de "traba- } \\
\text { lhar o esporte para além do esporte", desenvolvendo conceitos transversais como saúde e educa- } \\
\text { Futuro } \\
\text { ção. Atende hoje em torno de 7,1 mil crianças. }\end{array}$ \\
\hline $\begin{array}{c}\text { Lançar-se } \\
\text { para o }\end{array}$ & $\begin{array}{l}\text { Apoio ao Instituto Lançar-se para o Futuro, que atende anualmente cerca de 600 crianças, adoles- } \\
\text { centes e jovens na modalidade atletismo. Iniciado em 2010, esse patrocínio inclui um programa de } \\
\text { Futuro }\end{array}$ \\
$\begin{array}{c}\text { treinamento específico para adolescentes e jovens com potencial de alto rendimento em atletismo. } \\
\text { Programa } \\
\text { GR }\end{array}$ & $\begin{array}{l}\text { Parceria com o Sesi e Prefeitura de Toledo (PR), tem como foco o desenvolvimento de crianças, } \\
\text { lidade. Em 2010, foram beneficiadas cerca de 1,2 mil crianças e o projeto conta atualmente com } \\
29 \text { atletas na equipe de alto rendimento. }\end{array}$ \\
\hline
\end{tabular}

Fonte: Adaptado do Brasil Foods (2010). 
Observa-se que as iniciativas em prol do fomento a educação esportiva e desenvolvimento infantil é também uma preocupação da BRF que se traduz em projetos já consolidados. Considera-se ainda que as ações possuam um foco local, pois são desenvolvidas nas regiões onde a empresa possui unidades de negócio. Essas iniciativas apresentam uma orientação altruísta, pois a empresa não apresenta ganhos fi- nanceiros diretamente com essas ações. Entretanto, o possível ganho em termos de legitimidade e imagem de mercado pode ser considerado como ganho estratégico importante.

A seguir, na tabela 2, são apresentados os indicadores sociais externos com base dos dados financeiros do Balanço Social publicado pela empresa no modelo IBASE dos anos de 2009 e 2010.

Tabela 2 - Indicadores sociais externos do Balanço Social IBASE 2010

\begin{tabular}{l|ccc|ccc}
\hline & \multicolumn{3}{|c|}{2010} & \multicolumn{2}{c}{2009} \\
\hline $\begin{array}{l}\text { Indicadores sociais exter- } \\
\text { nos }\end{array}$ & $\begin{array}{c}\text { Valor } \\
\text { (R\$ milhões) }\end{array}$ & $\begin{array}{c}\text { \% sobre } \\
\text { FPB }\end{array}$ & $\begin{array}{c}\text { \% } \\
\text { sobre } \\
\text { RL }\end{array}$ & $\begin{array}{c}\text { Valor } \\
\text { (R\$ milhões) }\end{array}$ & $\begin{array}{c}\text { \% sobre } \\
\text { FPB }\end{array}$ & $\begin{array}{c}\text { \% so- } \\
\text { bre RL }\end{array}$ \\
\hline Educação & 0,85 & $0,08 \%$ & $0,00 \%$ & 1,34 & $0,18 \%$ & $0,01 \%$ \\
Cultura & 0 & $0,00 \%$ & $0,00 \%$ & 0,01 & $0,00 \%$ & $0,00 \%$ \\
Saúde e saneamento & 0,03 & $0,00 \%$ & $0,00 \%$ & 0,00 & $0,00 \%$ & $0,00 \%$ \\
$\begin{array}{l}\text { Esporte } \\
\text { Combate à fome e segurança } \\
\text { alimentar }\end{array}$ & 1,20 & $0,11 \%$ & $0,01 \%$ & 0,59 & $0,08 \%$ & $0,00 \%$ \\
$\begin{array}{l}\text { Outros } \\
\text { Total das contribuições para }\end{array}$ & 0,01 & $0,00 \%$ & $0,00 \%$ & 0,07 & $0,02 \%$ & $0,00 \%$ \\
a sociedade & 0,14 & $0,00 \%$ & $0,00 \%$ & 0,00 & $0,00 \%$ & $0,00 \%$ \\
Tributos (excluídos encargos & 2,23 & $0,22 \%$ & $0,01 \%$ & 2,00 & $0,27 \%$ & $0,01 \%$ \\
sociais) & $2.966,58$ & $196 \%$ & $13,08 \%$ & $3.019,85$ & $312 \%$ & $14,42 \%$ \\
\hline Total & $\mathbf{2 . 9 6 8 , 8 1}$ & $\mathbf{1 9 7 \%}$ & $\mathbf{1 3 , 0 9 \%}$ & $\mathbf{3 . 0 2 1 , 8 5}$ & $\mathbf{3 1 2 , 2 6 \%}$ & $\mathbf{1 4 , 4 3 \%}$ \\
\hline
\end{tabular}

Nota: FBP = Folha de Pagamento Bruta; RL = Receita Líquida.

Fonte: Adaptado do Balanço Social BRF (2010).

Com relação aos gastos feitos pela BRF no âmbito externo da dimensão social constata-se que ocorreu uma diminuição nos investimentos no ano de 2010 em relação a 2009. Dentre os indicadores observados, constata-se que os gastos com educação e combate à fome e segurança alimentar apresentaram decréscimos. Já os valores investidos em saúde e saneamento e esportes apresentaram incremento em relação a 2009. A maior parcela dos gastos sociais externos são os tributos pagos pela BRF. As contribuições para a sociedade realizadas pela BRF em 2010 totalizaram R \$ 2,23 milhões sendo apenas $0,01 \%$ da Receita Líquida da empresa.

\subsubsection{Desempenho ambiental}

$\mathrm{Na}$ dimensão ambiental, a BRF também apresenta um forte compromisso com a sustentabilidade. No ano de 2010 o valor investido pela empresa em ações com foco na gestão ambiental totalizou $\mathrm{R} \$$ 144,1 milhões. Os focos dos investimentos foram destinados para questões como prevenção e gestão ( $R$ \$ 24,3 milhões), destinação, tratamento e mitigação ( $\mathrm{R} \$ 74 \mathrm{mi}-$ lhões) e investimentos em florestas (R\$ 45,7 milhões). De acordo com o foco ambiental demonstrado pela empresa, são relatadas iniciativas relacionadas ao consumo de água, efluentes, consumo de energia, resíduos, coleta de embalagens, emis- 
sões atmosféricas e sistema suinocultura sustentável.

Com relação ao consumo de água, a BRF manteve estável a retirada desse recurso, mesmo aumentando sua produção. A BRF investe em processos que permitam a reutilização da água em suas operações. O índice de reutilização em 2010 foi de 20,4\%, semelhante ao de 2009 (20,2mento de produção de $6 \%$ pode-se considerar que sua eficiência no reuso da água aumentou. Em unidades como Capinzal (SC), a taxa de reuso chegou a $47 \%$ em 2010 . No município de Teutônia (RS) foi criado o Hidrotime, equipe multidisciplinar que avalia e propõe melhorias nos processos para utilização racional da água. O grupo contribuiu para a economia de $14 \%$ do total de água utilizada na unidade $\left(113,5 \mathrm{mil} \mathrm{m}^{3}\right)$. Outra ação da BRF é a prioridade na captação de água na superfície, evitando com isso a exploração dos mananciais subterrâneos e o uso de abastecimento público, que significa um consumo concorrencial com os seres humanos. Como isso, houve diminuição de $582.574 \mathrm{~m}^{3}$ no uso de água da rede pública. Ainda relacionado à água, todas as unidades da BRF possuem Estação de Tratamento de Efluentes. Com isso, a água é retornada ao meio ambiente dentro dos parâmetros legais.

Referente ao consumo energético, como resultado da implantação de 420 ações operacionais e de investimento a BRF alcançou uma economia de 341.496 GJ de energia elétrica em 2010 comparado a 2009 (redução de 4,78\%). O uso de energia direta pela BRF aumentou 3,8\% em 2010, mas esse acréscimo foi concentrado em fontes renováveis (mais 4,6\%), enquanto registrou-se decréscimo de $8,6 \%$ em energia provenientes de combustíveis fósseis. No ano, $94,89 \%$ de toda a energia consumida pela empresa foi gerada por fontes renováveis. No consumo indireto, a única energia utilizada pela BRF é a elétrica. Em 2010, houve acréscimo de 1,1\% no uso de energia indireta, sendo $89,8 \%$ proveniente de fonte renovável, mantendo o alinhamento à matriz energética nacional (Operador Nacional do Sistema - ONS).

Quando aos resíduos produzidos, apenas $3,86 \%$ do total produzido pela BRF, em 2010, foram destinados a aterros. Outra pequena parcela é processada internamente, de acordo com a legislação. $\mathrm{O}$ restante é encaminhado para reciclagem ou processamento externo feito por terceiros licenciados em órgãos ambientais. A seleção dos parceiros é feita de forma rigorosa onde a BRF controla as licenças e realiza ainda auditorias. Os resíduos produzidos pela BRF são classificados de acordo com a NBR 10.004 e controlados corporativamente. Quase a totalidade $(99,8 \%)$ pertence à Classe II (não perigosos) e é originário basicamente no processo produtivo, como resíduos orgânicos. $\mathrm{O}$ restante pertence à Classe I (perigosos), como lâmpadas, pilhas, baterias e resíduos produzidos nos ambulatórios existentes nas unidades.

Além do controle dos resíduos, a BRF também apresenta esforços importantes na coleta de embalagens. Em 2010 a empresa fechou uma parceria com a TerraCycle para uma campanha envolvendo os consumidores dedicara a reutilização de cartuchos de produtos congelados e potes de margarina. Após os consumidores efetuarem seus cadastros, a Brigada Perdigão se encarrega de recolher o material e o envia para a TerraCycle para ser transformado em produtos ecoamigáveis. A Brigada já está ativa em 20 estados, obteve 238 assinaturas (37\% de escolas e $30 \%$ de famílias), e recolheu 1.947 embalagens em três meses.

Outro ponto importante nas iniciativas em prol do desempenho ambiental são as ações de controle e redução de emissões atmosféricas. A BRF se prepara para realizar seu inventário de emissões relativo a 2010, com base no Greenhouse Gas Protocol Initiative (GHG). Esse inventário dará condições para fazer um diagnóstico dos processos e sistemas e traçar uma estratégia de longo prazo destinada à gestão dos GEE (Gazes do Efeito Estufa). 
Como resultado de suas ações, a BRF foi incluída no Índice de Carbono Eficiente (ICO2), da BM\&FBovespa, criado em 2010 para incentivar as empresas a migrarem para um sistema de produção de baixo carbono. Além disso, a BRF procura construir centros de distribuição próximos aos locais de consumo e de fornecimento. Sua frota de caminhões está sempre rodando com a carga completa, eliminando o desperdício e reduzindo o impacto no meio ambiente. Inspeções feitas na frota da Empresa indicaram que $87 \%$ dos veículos operavam de acordo com a legislação e os padrões de qualidade.

O projeto denominado Sistema Suinocultura Sustentável é considerados um dos projetos mais amplos e importantes da BRF por aliar aspectos sociais, econômicos e ambientais. Com o apoio à construção de biodigestores nas propriedades dos produtores integrados, a BRF desenvolve um programa estruturado de redução de emissões de GEE, que deve ser amplia- do para toda a sua cadeia de fornecimento de suínos. Por meio do projeto, os agricultores adotam os Mecanismos de Desenvolvimento Limpo (MDL), reduzindo o impacto dos dejetos da suinocultura no meio ambiente. A medida faz parte da meta de reduzir emissão de dióxido de carbono $(\mathrm{CO} 2)$ em toda a cadeia de produção, fornecimento e distribuição. Considerando os projetos já implantados, o potencial de redução é de 591.418 toneladas anuais de CO2eq, de acordo com a metodologia da ONU. Em 2010, a redução chegou a 137.870 toneladas de $\mathrm{CO}$ eq. O projeto faz parte de uma lista de 50 iniciativas globais do setor privado destacadas pela ONU, pois tem impacto na redução da pobreza e melhoria nas condições de vida.

Dando continuidade à análise do desempenho ambiental da BRF, na tabela 3 , são apresentados os indicadores ambientais com base dos dados financeiros do Balanço Social publicado pela empresa no modelo IBASE dos anos de 2009 e 2010.

Tabela 3 - Indicadores ambientais do Balanço Social IBASE 2010

\begin{tabular}{l|ccc|ccc}
\hline & \multicolumn{3}{|c|}{2010} & \multicolumn{3}{c}{2009} \\
\hline Indicadores ambientais & $\begin{array}{c}\text { Valor } \\
\text { (R\$ milhões) }\end{array}$ & $\begin{array}{c}\text { \% sobre } \\
\text { FPB }\end{array}$ & $\begin{array}{c}\text { \% sobre } \\
\text { RL }\end{array}$ & $\begin{array}{c}\text { Valor } \\
\text { (R\$ milhóes) }\end{array}$ & $\begin{array}{c}\text { \% sobre } \\
\text { FPB }\end{array}$ & $\begin{array}{c}\text { \% so- } \\
\text { bre RL }\end{array}$ \\
\hline $\begin{array}{l}\text { Investimentos relacionados } \\
\text { com a produção/ operação da } \\
\text { empresa }\end{array}$ & 144,14 & $14,40 \%$ & $0,64 \%$ & 111,46 & $15,21 \%$ & $0,53 \%$ \\
$\begin{array}{l}\text { Investimentos em programas } \\
\text { e/ou projetos externos }\end{array}$ & 0,00 & $0,00 \%$ & $0,00 \%$ & 0,38 & $0,05 \%$ & $0,00 \%$ \\
\hline Total & $\mathbf{1 4 4 , 1 4}$ & $\mathbf{1 4 , 4 0 \%}$ & $\mathbf{0 , 6 4 \%}$ & $\mathbf{1 1 1 , 8 4}$ & $\mathbf{1 5 , 2 6 \%}$ & $\mathbf{0 , 5 3 \%}$ \\
\hline
\end{tabular}

Nota: FBP = Folha de Pagamento Bruta; RL = Receita Líquida.

Fonte: Adaptado do Balanço Social BRF (2010).

Pode-se observar que a BRF apresentou uma elevação nos investimentos feitos em ações de cunho ambiental. Entretanto, todos os investimentos feitos em 2010 foram destinados para projetos e ações com foco na produção e operações da empresa. Isso demonstra que essas ações possuem uma orientação estratégica, pois a empresa busca ganhos estratégicos e operacionais com suas ações ambientais.
No ano de 2010 a empresa apresentou um crescimento de $29,32 \%$ em relação a 2009.

\subsubsection{Desempenho econômico-financeiro}

Em termos econômicos e financeiros, a BRF é considerada uma empresa consolidada e com participações significativas de mercado no segmento de alimentos processados. Nesta subseção apresenta dados referentes ao desempenho econômico e financeiro da BRF. Dessa forma, o 
Responsabilidade social e desenvolvimento sustentável: Um estudo de caso em uma companhia brasileira de alimentos processados

estudo contempla as três dimensões bases do TBL. A seguir, na tabela 4, são apresentados os indicadores econômicos e finan- ceiros publicados pela empresa nos anos de 2009 e 2010.

Tabela 4 - Indicadores econômicos do Balanço Social IBASE 2010

\begin{tabular}{l|c|c}
\hline Indicadores econômicos & $\mathbf{2 0 1 0}$ (Valor em R\$ milhões) & 2009 (Valor em R\$ milhões) \\
\hline Receita líquida (RL) & 22.681 & 20.937 \\
Resultado operacional (RO) & 1.001 & 733 \\
Folha de pagamento bruta (FPB) & 3.525 & 3.155 \\
Lucro Líquido & 804 & 123 \\
Valor de Mercado * & 25.850 & 39.580 \\
EBITDA & 2.635 & 871 \\
\hline
\end{tabular}

Nota: * dados referentes a dezembro.

Fonte: Adaptado do Balanço Patrimonial (2010) e Demonstrativo de Resultado (2010)

Em termos financeiros a empresa apresenta um desempenho altamente positivo. Com receita líquida de $\mathrm{R} \$ 22.681$ milhões em 2010, apresentou um crescimento de $8,33 \%$. Além disso, os valores de resultado operacional e folha de pagamento bruta também apresentaram aumento de valor em 2010 em comparação a 2009. Outro ponto que merece atenção é o lucro líquido que apresentou um valor de $\mathrm{R} \$ 804$ milhões em 2010, apresentando um crescimento de $553,66 \%$ em relação a 2009 . O valor de mercado da empresa em dezembro de 2010 foi de $R \$ 25.850$ milhões, apresentando um decréscimo de 34,69\% em relação a 2009. Entretanto, outro valor de grande importância para a avaliação financeira empresarial, o EBITDA (Earnings Before Interest, Taxes, Depreciation and Amortization) em 2010 apresentou uma cifra de R $\$ 2.635$ milhões demonstrando um crescimento de $202,53 \%$ em relação a 2009.

\section{Considerações finais}

As ações de RSC são cada vez mais comuns e as grandes corporações desempenham um papel fundamental no atendimento das necessidades da sociedade assim como na manutenção de um ambiente ecológico que não afete as gerações futuras. Todavia, as organizações podem apresentar posturas e preocupações diferenciadas em termos de RSC e DS. O alinhamento existente entre as ações empresariais de RSC e as necessidades mais urgentes de sustentabilidade é ainda tema que necessita de investigações. A orientação predominante ainda é estratégica e financeira e as necessidades sociais e ambientais ainda são apenas parcialmente atendidas.

Este estudo objetivou descrever as iniciativas de RSC e sustentabilidade da BRF efetuando um confronto entre a teoria e a prática. Essas contribuições se justificam pela necessidade de um aprofundamento empírico relacionado ao tema de estudo como forma de consolidar os pressupostos teóricos existentes. Além disso, a consolidação de práticas e iniciativas de RSC e DS é importante para que se obtenha um entendimento maior de seus impactos na sociedade assim como para o desempenho organizacional.

Os resultados do estudo sugerem que a BRF apresenta um posicionamento consolidado em termos de RSC e DS. Suas iniciativas em formato de programas e planos de ação demonstram um compromisso social e ambiental. No entanto, considerase que suas ações são voltadas para as comunidades locais onde a empresa possui unidades de negócio. Além disso, os resultados da análise das ações da empresa sugerem que ela apresenta uma orientação 
estratégica em suas iniciativas de RSC. Assim, a empresa objetiva ganhos econômicos e financeiros em grande parte de suas iniciativas e investimentos.

Outro ponto que merece atenção são as ações da empresa que buscam o desenvolvimento de uma cadeia produtiva sustentável. Por meio de ações e investimentos destinados a produtores rurais (Sistema Suinocultura Sustentável) e foco nos fornecedores da cadeia (programa Supply Chain de Classe Mundial) a empresa busca o desenvolvimento sustentável da cadeia por meio de ganhos sociais, ambientais e econômicos. Considera-se, no entanto, que a empresa estudada poderia destinar parte de seus investimentos para ações sociais e ambientais mais urgentes e que vão além das localidades de suas unidades de negócio, configurando assim ações de cunho altruísta.

Limitações importantes são observadas neste estudo. Primeiramente chamase a atenção para o fato de o estudo ter sido realizado em uma única empresa o que limita suas conclusões e generalizações. Além disso, o fato de as investigações serem baseadas apenas em dados secundários também fragiliza os resultados e as conclusões do estudo. Finalmente, por se tratar de um estudo que tomou como ano base o ano de 2010, as constatações obtidas podem não refletir as reais contribuições da empresa em termos longitudinais.

Sugere-se, portanto, que estudos adicionais sejam conduzidos com outras empresas do setor de alimentos processados assim como empresas atuantes a jusante e a montante da cadeia produtiva da BRF. Além disso, a realização de entrevistas com dirigentes e gestores dessas organizações permitirá uma melhor compreensão das orientações das ações de RSC e sustentabilidade realizadas. Por fim, a condução de investigações longitudinais por meio de análises documentais históricas poderá sanar a deficiência da investigação de um único ano, o que não permite avaliar os impactos das ações e iniciativas no médio e longo prazo.

\section{Referências}

BALANÇO SOCIAL BRF - Balanço Social da Brasil Foods 2010 - modelo IBASE. Disponível em < http://www.brasilfoods.com>. Acesso em 20 de outubro de 2011.

BENDIXEN, M.; ABRATT, R. Corporate identity, ethics and reputation in supplierbuyer relationships. Journal of Business Ethics, v. 76, p. 69-82, 2007.

BM\&F BOVESPA - Bolsa de Mercados e Futuros e Bolsa de Valores do Estado e São Paulo. Disponível em < http://www.bmfbovespa.com.br>. Acesso em 15 de dezembro de 2011.

BRASIL FOODS - Relatório Anual 2010. Disponível em < http://www.brasilfoods.com>. Acesso em 20 de outubro de 2011.

CARROLL, A. Corporate Social Responsibility: Evolution of a Definitional Construct. Business \& Society, v. 38, n. 3, p. 268-295, 1999.

CARROLL, A. The pyramid of corporate social responsibility: toward the moral management of organizational stakeholders. Business Horizons, v. 34, n. 4, p. 3448, 1991.

CARROLL, A. Three Dimensional conceptual model $f$ corporate performance. Academy of Management Review, v. 4, p. 497-505, 1979.

CARTER, C. R.; CARTER, J. R. Interorganizational determinants of environmental purchasing: Initial evidence from the consumer products industries. Decision Sciences, v. 29, n. 3, p. 659-684, 1998.

DAVIS, K.; BLOMSTROM, R.L. Business and Society: Environment and Re- 
Responsabilidade social e desenvolvimento sustentável: Um estudo de caso em uma companhia brasileira de alimentos processados

sponsibility. 3rd edition. New York: Mc Graw Hill Series in Management, 1975.

ELKINGTON, J. Cannibals with Forks: The Triple Bottom Line of 21st Century Business, Stony Creek, CT: New Society Publishers, 1998.

FREDERICK, W.C. From CSR1 to CSR2. Business and Society, v. 33, n. 2, p. 150164, 1994.

FREEMAN, E. Strategic Management: a stakeholder approach. Boston. Pitman, 1984.

GALBREATH, J. Building corporate social responsibility into strategy. European Business Review, v. 21, n. 2, p. 109-127, 2009.

GAWOR, L. Globalization and its Alternatives: Antiglobalism, Alterglobalism and the Idea of Sustainable Development. Sustainable Development, v. 16, p. 126-134, 2008.

JONES, T. M.; WICKS, A. C. Convergent stakeholder theory. Academy of Management Review, v. 24, n. 2, p. 206-221, 1999.

LANTOS, G. P. The boundaries of strategic corporate social responsibility. Journal of Consumer Marketing, v. 18, n. 7, p. 595-632, 2001.

NEVES, J.; BENTO, L. Traditional values and the pressures of transformation. In HABISH, A., JONKER, J.; WEGNER, M.; SCHIMPETER, R. (Eds.). Corporate social Responsibility across Europe. Hiedelberg: Springer Berlin, 2005.

NEWELL, P.; MURO, A. Corporate Social and Environmental Responsibility in Argentina. Journal of Corporate Citizenship. Winter: v. 24, p. 49-68, 2006.

PRESTON, L.E. Corporation and Society: The Search for a Paradigm. Journal of Economic Literature, v. 13, n. 2, p. 434453, 1975.
PRETEZ-BATRES, L.A.; MILLER, V.V.; PISANI, M.J. CSR, Sustainability and the Meaning of Global Reporting for Latin American Corporations. Journal of Business Ethics, v. 91, p. 193-209, 2010.

SCHAEFER, A. Corporate Sustainability Integrating Environmental and Social Concerns? Corporate Social Responsibility \& Environmental Management. v. 11, n. 4, p. 179-187, 2004.

SCHWARTZ, M. S., CARROLL, A. B. Integrating and Unifying Competing and Complementary Frameworks: The Search for a Common Core in the Business and Society Field. Business \& Society, v. 47, n. 2, p. 148-186, 2008.

SETHI, S. P. A conceptual framework for environmental analysis of social issues and evaluation of business and evaluation of business response patterns. Academy of Management Review, v. 4, n. 1, p. 63-74, 1979.

STEAD, J. G.; STEAD, E. Eco-enterprise strategy: standing for sustainability. Journal of Business Ethics, v. 24, p. 313-329, 2000 .

TENCATI, A., ZSOLNAI, L. The Collaborative Enterprise. Journal of Business Ethics, n. 85, p. 367-376, 2009.

TENÓRIO, F. G. Responsabilidade social empresarial: teoria e prática. $2^{\mathrm{a}}$ ed. Rio de Janeiro: Editora FGV, 2006.

VELASQUEZ, M. G. Business ethics: Concepts and cases. 6 ed. Upper Saddle River, NJ: Prentice Hall, 2006.

WAGNER, M. How to Reconcile Environmental and Economic Performance to Improve Corporate Sustainability: Corporate Environmental Strategies in the European Paper Industry. Journal of Environmental Management. v. 76 , n. 2, p. 105-118, 2005.

WCED - World Commission on Environmental and Development. Our Common 
Future. New York: Oxford University Press, 1987.

YIN, R. Estudo de caso: planejamento e métodos. 3 ed. Porto Alegre: Bookmann, 2005. 